\title{
ANÁLISE DA PRODUÇÃO CIENTÍFICA SOBRE CRIATIVIDADE EM PROGRAMAS BRASILEIROS DE PÓS-GRADUAÇÃO EM PSICOLOGIA (1994 - 2001)
}

\author{
Andréa Vieira Zanella* \\ Andréia Piana Titon ${ }^{\#}$
}

\begin{abstract}
RESUMO. Considerando-se a importância da criatividade na sociedade contemporânea, realizou-se esta pesquisa com o objetivo de investigar o que foi produzido sobre a temática entre 1994 e 2001 nos programas de pós-graduação em Psicologia no Brasil. Foram analisados 68 resumos de teses/dissertações, disponíveis na base de dados da Capes. Os resumos foram analisados conforme as categorias identificação, tipo de estudo, temática principal, linguagem artística e referencial teórico. Contatou-se que há uma concentração de trabalhos realizados nas regiões Sudeste e Centro-Oeste do Brasil. Observou-se uma predominância de estudos experimentais (39\%), levantamentos $(27,1 \%)$ e estudos de caso (18,6\%). Quanto à temática enfocada houve certa variação, com trabalhos em diferentes áreas, destacando-se os referentes à prática pedagógica (39,7\%). Com relação às abordagens teóricas, as mais utilizadas foram a psicométrica $(33,8 \%)$ e a psicanalítica $(19,1 \%)$. Constatou-se, por fim, o crescimento do número de teses/dissertações defendidas nesses últimos anos sobre criatividade, o que pode indicar um maior interesse pela temática.
\end{abstract}

Palavras-chave: criatividade, pesquisa "estado da arte", psicologia.

\section{ANALYSIS OF THE SCIENTIFIC PRODUCTION ON CREATIVITY IN GRADUATE STUDY PROGRAMS IN PSYCHOLOGY (1994 - 2001)}

\begin{abstract}
Considering the importance of the creativity in the contemporary society, the purpose of this research was to investigate abstracts of dissertations and theses on creativity produced in the Graduate Study Programs of Psychology in Brazil from 1994 through 2001. Sixty-eight summaries of dissertations and theses, available in CAPES database, were analyzed. The summaries were analyzed according to categories: Identification, Type of Study, Theme, Language and Theoretical Approach. It was noted that there is a concentration of studies carried out in the Southeastern region of Brazil. It was observed a predominance of Experimental Studies (39\%), Surveys (27,1\%) and Case Studies (18,6\%). Regarding the theme, there was diversity, including papers in different areas, with emphasis on Pedagogical Practices $(39,7 \%)$. Regarding theoretical approaches, the Psychometric $(33,8 \%)$ and Psychoanalytic $(19,1 \%)$ were the most applied. It was observed an increase in the number of theses and dissertations on creativity, defended in the previous years, which indicates an increasing interest in the area.
\end{abstract}

Key words: creativity, "state of the art" research, psychology.

Criatividade é um tema que vem suscitando o interesse de pesquisadores de diferentes campos de saber, entre eles a Psicologia. Alencar e Fleith (2003) afirmam que as contribuições teóricas mais divulgadas e discutidas em relação à literatura sobre Psicologia da Criatividade no Brasil são as da teoria psicanalítica, da Gestalt, dos representantes da Psicologia Humanista, bem como estudos que investigam o papel dos hemisférios cerebrais na produção criativa. Destacam as autoras que, nos últimos 20 anos, surgiram novas contribuições teóricas, com ênfase na influência de fatores sociais, culturais e históricos no desenvolvimento da criatividade, sendo que até os anos 1970 a ênfase era no perfil do indivíduo criativo e no desenvolvimento de programas e técnicas que favorecessem a expressão criativa.

Afirmam ainda as autoras terem sido desenvolvidas nestes últimos anos teorias que apresentam uma visão mais sistêmica do fenômeno

* Docente do Departamento de Psicologia e do Programa de Pós-Graduação em Psicologia da Universidade Federal de Santa Catarina-UFSC, Doutora em Psicologia da Educação, bolsista de produtividade em pesquisa do CNPq.

\# Acadêmica do Curso de Psicologia da Universidade Federal de Santa Catarina-UFSC, Bolsista PIBIC/CNPq-BIP/UFSC. 
criatividade, com destaque para três modelos de criatividade: a teoria de investimento em criatividade de Sternberg, o modelo componencial de criatividade de Amabile e a perspectiva de sistemas de Csikszentmihalyi. Resguardadas as devidas diferenças, estas teorias ressaltam o papel ativo do sujeito no processo criativo e enfatizam os fatores sociais, culturais e históricos no processo de criação e na avaliação do produto criativo.

Para a teoria de investimento em criatividade, proposta por Sternberg e por Lubart na década de 1990, considera-se o comportamento criativo como resultado da inter-relação de seis fatores: da inteligência, dos estilos intelectuais, do conhecimento, da personalidade, da motivação e do contexto ambiental. (Alencar \& Fleith, 2003).

O modelo componencial de criatividade, proposto por Amabile nas décadas de 1980 e 1990, define a criatividade a partir de aspectos como originalidade e adequação da resposta, além da possibilidade de vários caminhos para a solução da resposta. Discute a influência no processo criativo dos fatores cognitivos, de personalidade e, principalmente, dos fatores sociais e do papel da motivação. Neste modelo teórico, enfatiza-se a interação de três componentes no processo criativo: as habilidades de domínio, os processos criativos relevantes e a motivação intrínseca (Alencar \& Fleith, 2003).

A perspectiva de sistemas, proposta por Csikszentmihalyi, defende o estudo da criatividade com foco nos sistemas sociais, e não nos indivíduos. $O$ fundamental nesta proposta é investigar onde a criatividade se encontra e de que forma o ambiente social, cultural e histórico reconhece ou não uma produção criativa. Nesta perspectiva, a criatividade é entendida como um ato, idéia ou produto que transforma ou modifica um domínio existente. Para que isso aconteça é fundamental os sujeitos terem acesso aos sistemas simbólicos e o contexto social ser receptivo a novas idéias (Alencar \& Fleith, 2003).

De acordo com Santeiro, Santeiro e Andrade (2004), os estudos sobre a temática criatividade já foram caracterizados por enfoque unidimensional e por uma diversidade de definições, mas têm caminhado para uma visão mais ampla, voltada para seus diversos aspectos e com enfoque multidimensional. Para compreender a criatividade, destacam os autores, é fundamental visualizar a interação dinâmica entre as características das pessoas (personalidade, habilidades cognitivas) e o contexto onde estão inseridas (família, escola, trabalho).

Considerando a importância de se evidenciarem as tendências das pesquisas sobre criatividade no Brasil, investigamos o que vem sendo produzido nos últimos anos no âmbito dos programas de pósgraduação em Psicologia ${ }^{1}$ sobre a temática.

Delimitamos esta investigação ao período de 1994 a 2001, pois identificamos em consulta a bases de dados uma dissertação de mestrado (Santos, 1995) que investiga parte da produção científica da criatividade em programas de pós-graduação de Psicologia e Educação entre 1970 e 1993. Neste estudo a autora analisou 59 resumos de teses e dissertações sobre criatividade, em programas de pós-graduação em Psicologia e Educação de todas as instituições de pósgraduação no Brasil, nos anos de 1970 a 1993. Entre os resultados a autora constatou que a maior parte dos trabalhos tratam de estudos empíricos. Além disso, as abordagens mais utilizadas são a comportamental e a psicométrica, sendo que, dos estudos empíricos, a maioria são pesquisas experimentais realizadas com maior freqüência em escolas, com alunos de $5^{\mathrm{a}}$ a $8^{\mathrm{a}}$ séries do Ensino Fundamental. Propomos neste estudo continuar a investigação sobre a produção científica entre 1994 e 2001, procurando evidenciar continuidades e rupturas em relação às tendências evidenciadas por Santos (1995).

\section{MÉTODO}

Esta pesquisa caracteriza-se como "estado da arte" ou "estado do conhecimento". De caráter bibliográfico, este tipo de pesquisa se propõe mapear e discutir certa produção acadêmica em determinado campo do conhecimento, na tentativa de responder quais aspectos e dimensões vêm sendo destacados e privilegiados em determinada época e lugar. Tais pesquisas são também reconhecidas por utilizarem procedimentos de caráter inventariante e descritivo sobre o tema investigado, incidindo as análises sobre dissertações/teses, publicações em periódicos e comunicações em anais de congressos e de seminários (Ferreira, 2002).

Optou-se pela análise de resumos de teses e dissertações dos programas de pós-graduação em Psicologia no Brasil reconhecidos pela Coordenação de Aperfeiçoamento de Pessoal de Nível Superior Capes (2004), no período entre 1994 e 2001. A delimitação do ano de 2001 como período final se deve ao fato de que a base de dados da Capes (2004) não disponibilizou, até outubro de 2004, resumos de trabalhos realizados após esse ano.

1 A área da Educação está sendo investigada em outro projeto de Iniciação Científica (PIBIC/UFSC) por uma acadêmica do curso de Pedagogia, orientada pela prof. Dra. Sílvia Zanatta Da Ros. 


\section{PROCEDIMENTOS}

Buscaram-se no portal da Capes (2004) todas as instituições de ensino superior (IESs) do Brasil com algum programa de pós-graduação em Psicologia reconhecido por aquela entidade. A partir disso, foram obtidos todos os resumos de dissertações e teses das IESs selecionadas que apresentavam relação com a temática da pesquisa, a partir das seguintes palavraschave: criatividade, atividade criadora, processos de criação, estética.

Na primeira busca na base de dados foram obtidos cento e vinte e quatro resumos que apresentavam as palavras-chave relacionadas. Destes, inicialmente foram selecionados somente aqueles que citavam o termo criatividade entre as palavras-chave do resumo, somando quarenta e um resumos (Tabela $1 \mathrm{em}$ anexo). Considerando-se a grande quantidade de resumos que seriam excluídos por não citarem criatividade como palavra-chave, foi realizada nova leitura dos mesmos e identificados aqueles que apresentavam a criatividade ou processos criativos como tema, selecionando-se desta forma mais vinte e sete resumos (Tabela $2 \mathrm{em}$ anexo). A partir dessa primeira caracterização do material de estudo, feita em conformidade com os procedimentos adotados por Santos (1995), foram delimitadas as seguintes categorias para a análise dos resumos: identificação, tipo de estudo, principal tema em foco, linguagem artística e referencial teórico. Essas mesmas categorias, no entanto, foram analisadas no que se refere à sua adequação em relação ao material analisado, procedendo-se então às modificações necessárias à contemplação da diversidade dos resumos das teses/dissertações investigados.

$\mathrm{Na}$ categoria identificação foram especificados: título, autor(a), orientador(a), nível (mestrado ou doutorado), instituição, programa e ano.

$\mathrm{Na}$ categoria tipo de estudo discorda-se da divisão entre estudos teóricos e empíricos, tal como proposta por Santos (1995). Conforme Minayo (1999), a divisão entre estudos teóricos e empíricos pressupõe uma falsa oposição e cisão entre teoria e prática; esta é falsa na medida em que pesquisas teóricas podem ter importantes conseqüências práticas e pesquisas aplicadas certamente têm implicações e contribuições teóricas.

Mantiveram-se, no entanto, as categorias estudos téoricos, pesquisa documental, pesquisa "Ex-postfacto", levantamentos e estudos de caso, propostas por Santos, de modo a identificar continuidades e rupturas com os anos anteriores. Desse modo, como estudos teóricos foram considerados aqueles que "analisam um determinado objeto de estudo ou conceito à luz de uma revisão de literatura ou de teorias existentes e estudos que realizam análises críticas a respeito de posições teóricas." (p. 26); a categoria pesquisa documental congrega estudos que se caracterizam pela análise de documentos; pesquisa experimental: "abrange a manipulação de uma ou mais variáveis. Determina um objeto de estudo, seleciona as variáveis que seriam capazes de influenciá-lo, define as formas de controle e de observação dos efeitos que a variável produz no objeto." (Santos, 1995, p. 25); as pesquisas "ex-postfacto" realizam um estudo sobre situações, consideradas experimentais, que ocorreram naturalmente; Levantamentos: estudos sobre um determinado objeto a partir do questionamento de pessoas; estudos de caso: pesquisas que realizam um estudo amplo e exaustivo sobre determinado(s) objeto(s). Por fim, na categoria outros foram agrupados aqueles estudos que não se enquadram em nenhuma das categorias anteriores.

Os estudos também foram categorizados conforme o lócus de investigação e o público alvo da pesquisa. Para o lócus de investigação foram encontradas as categorias: instituição de ensino regular (inclui Educação Infantil, Ensino Fundamental e Ensino Médio); instituição de ensino superior; contextos artísticos específicos; instituições (psiquiátricas, por exemplo); projetos sociais;organizações e empresas; e não passível de classificação.

Com relação ao público alvo, foram elencadas as seguintes subcategorias: alunos; professores/educadores (incluindo os que atuam em contextos educacionais formais e não formais); alunos e professores; empregados em empresas/organizações; usuários de instituições; artistas; grupos; e outros.

Com relação à Temática Principal, após a leitura e identificação das temáticas trabalhadas em cada pesquisa, foram criadas as categorias: prática pedagógica; prática psicológica na Saúde; prática psicológica nas empresas/organizações; vivências estéticas/criativas; avaliação/caracterização do sujeito criativo; concepções de criatividade/criação; outros.

Quanto à linguagem artística abordada nos trabalhos, foram formuladas as seguintes categorias: artes plásticas/visuais; dança/biodança; literatura; música; teatro; linguagens híbridas; e não passível de classificação. Utilizou-se esta categoria em função da frequiência com que as linguagens artísticas aparecem nos trabalhos que tratam da temática investigada, sendo que a categorização dos trabalhos permite identificar se algum tipo de linguagem artística vem 
sendo privilegiado nas pesquisas de mestrado/doutorado.

Para classificar os estudos em relação ao referencial teórico, foram utilizadas as categorias propostas por Santos e criadas outras a partir do levantamento do referencial teórico citado em cada resumo. Foram usadas as seguintes categorias: abordagem psicométrica, que inclui "estudos sobre variáveis psicológicas a partir da aplicação de testes ou escalas padronizadas." (Santos, 1995, p. 26); abordagem fenomenológica: "caracteriza-se por ter como tema o fenômeno entendido como único objeto experiencial possível, cujo sentido e essência deverão ser desvelados para se chegar à 'coisa mesma', através do hermenêutico, rigososo" (Santos, 1995, p. 27); abordagem histórico-cultural: ênfase nos processos históricos culturais e no método dialético; abordagem psicanalítica, categoria esta que inclui representantes de diferentes escolas da psicanálise, como Winnicott, Lacan, Klein e Freud; não passível de classificação inclui os resumos que não especificaram o referencial teórico utilizado no trabalho; e outras.

\section{RESULTADOS E DISCUSSÃO}

A apresentação dos dados diz respeito ao total dos trabalhos analisados nesta pesquisa, a saber, 68 resumos, sendo 41 estudos que utilizam a palavra criatividade como palavra-chave e 27 que utilizam a criatividade como tema. Serão apresentadas as porcentagens em cada categoria, pois se trata de um estudo exploratório. Quanto à distribuição dos trabalhos por unidade da Federação, constatou-se que há uma concentração da produção acadêmica brasileira em Psicologia sobre a temática criatividade, entre 1994 e 2001, no Estado de São Paulo (70\% dos trabalhos analisados). O Estado do Rio de Janeiro concentra $12 \%$ das produções, o Distrito Federal $10 \%$, o Rio Grande do Sul 7\% e Minas Gerais, 1\%. Não foram encontradas pesquisas sobre o tema em outros estados brasileiros no período analisado.Se considerarmos as regiões brasileiras, constata-se que $83 \%$ dos trabalhos analisados foram produzidos na Região Sudeste. Isso pode estar relacionado com a concentração de universidades pioneiras em pesquisa nessa região, com programas de pós-graduação já consolidados. Francisco (2002), ao investigar o "estado da arte" sobre dificuldades de aprendizagem escolar, também verificou a concentração de pesquisas nessa região.

Em relação às universidades onde os trabalhos analisados foram produzidos, destacam-se a Pontifícia Universidade Católica de Campinas (PUCCAMP), com a produção de $26,4 \%$ das teses e dissertações; a Pontifícia Universidade Católica de
São Paulo (PUC-SP), com 20,6\% dos trabalhos; a Universidade de São Paulo (USP), com 19,1\%; a Universidade de Brasília (UnB), com 8,8\%; a Pontifícia Universidade Católica do Rio Grande do Sul (PUC-RS), a Pontifícia Universidade Católica do Rio de Janeiro (PUC-Rio) e a Universidade Federal do Rio de Janeiro (UFRJ), com 5,9\% dos trabalhos cada. As demais, Universidade Federal do Rio Grande do Sul (UFRGS), Universidade Federal de Minas Gerais (UFMG), Universidade Católica de Brasília (UCB) e a Universidade Metodista de São Paulo (UMESP), juntas, concentram 7,4\% da produção acadêmica analisada.

Conforme a Figura 1, verifica-se que a produção no mestrado teve uma pequena variação durante os anos de 1994 a 1999, a qual oscilou entre cinco e sete dissertações defendidas por ano. Essa produção teve um aumento significativo no ano 2000, passando para dez dissertações defendidas nesse ano. Em relação às teses de doutorado, durante os anos de 1994 a 1998 e em 2001, encontrou-se no máximo uma produção por ano; destacam-se o ano de 1999, com três teses, e o ano de 2001, com 8 teses.

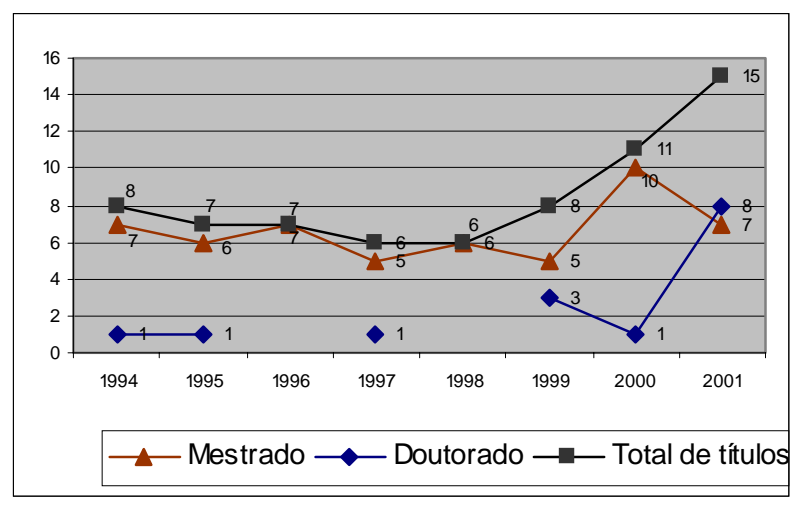

Figura 1. Quantidade total de títulos ao longo do tempo considerando Mestrado e Doutorado.

Observa-se, em relação ao total de títulos (figura 1), que houve um aumento no número de teses e dissertações a partir de 1999, o que pode estar relacionado a um maior interesse dos pesquisadores pela temática. Isso também pode estar relacionado com o contexto da sociedade contemporânea que estaria trazendo a criatividade à tona devido às demandas impostas pela "(...) modificação constante das técnicas de produção e por uma necessidade permanente de invenções" (Ponce, citado por Vasconcelos, 2001). Mas essa tendência somente poderá ser confirmada com novas pesquisas.

Em relação aos orientadores das teses e dissertações analisadas, constatou-se que onze professores orientaram $63,3 \%$ delas, considerando-se 
aqueles que orientaram dois ou mais trabalhos. Destaca-se nessa relação (Ver Tabelas 1 e 2) a professora Solange Muglia Wechsler, da PUCCAMP, com $22 \%$ do total das produções analisadas; Gilberto Safra, da PUC-SP, com 7,5\%; Eunice M. L. S. de Alencar, com 5,9\% (UCB e UnB); Edda Bomtempo (USP), João Augusto Frayze-Pereira (USP) e Suely Belinha Rolnik (PUC-SP) com 4,5\% cada; Albertina Mitjáns Martinez (UNB), Juracy Cunegatto Marques (PUC-RS), Lúcia Rabelo de Castro (UFRJ), Luis Cláudio Mendonça Figueiredo (PUC-SP) e Maria Helena Mira Novaes (PUC-Rio) com 2,9\% cada. A distribuição dos demais $36,7 \%$ das pesquisas analisadas se deu entre professores que orientaram apenas uma dissertação ou tese.

Quanto à categoria tipo de estudo, contatou-se que $39 \%$ das pesquisas analisadas são representados por: pesquisa experimental; 27,1\%, levantamentos; 18,6\%, estudos de caso; $13,2 \%$, estudos teóricos; $8,5 \%$, pesquisa documental; e 1,7 \%, pesquisa "ex-post-facto". Entre as pesquisas classificadas como outras $(5,1 \%)$ foram citadas a "pesquisa-ação" e a "pesquisa de campo". Esses índices aproximam-se dos resultados encontrados por Santos (1995), no período de 1970 a 1993, quando constatou que somente $18,64 \%$ dos estudos eram teóricos. Contribuíram para a manutenção dessa tendência as características dos programas de pós-graduação no Brasil, que vêm reduzindo significativamente, nas últimas décadas, o tempo para titulação. Estudos teóricos requerem experiência e fundamentação teórica consistente dos pesquisadores, o que nem sempre é possível consolidar no espaço de tempo de um mestrado ou mesmo de um doutorado.

Na investigação de Santos (1995) também a pesquisa experimental e os levantamentos apareceram com maior freqüência que os demais tipos de estudo. A diferença de percentuais, no entanto, é significativa: enquanto de 1970 a 1993 constatou-se que $62,5 \%$ das pesquisas sobre criatividade eram experimentais, na última década estas ficaram em $39 \%$. Os levantamentos, por sua vez, tiveram discreto crescimento, passando de $25 \%$ para $27,1 \%$, assim como as pesquisas documentais, que passaram de $5 \%$ para $8,5 \%$. Os estudos de caso é que tiveram um aumento considerável: enquanto nas décadas de 70, 80 e 90 restringiram-se a $5 \%$ das pesquisas investigadas, na última década (94 a 2001) corresponderam a 18,6\% das teses e dissertações analisadas.

Com relação ao lócus de investigação, obtiveram-se os seguintes resultados: $25 \%$ foram realizados em instituições de ensino regular; $23,7 \%$ em contextos artísticos específicos; $18,6 \%$ em instituições de ensino superior; 10,2\% em instituições; 8,5\% em organizações/empresas; $1,7 \%$ em projetos sociais. Além disso, 7 (11,9\%) dos estudos que não se caracterizavam como teóricos não foram passíveis de classificação, pois nos resumos não constavam os locais de investigação.

Santos (1995), ao realizar a categorização dos trabalhos produzidos de 1970 a 1993, encontrou 48 trabalhos empíricos, dos quais 19 não foram passíveis de classificação quanto ao lócus de investigação. Entre os que ela classificou, 96,5\% foram realizados em escolas. Disso se constata que houve, na última década, uma diversificação quanto aos locais em que foram realizadas as pesquisas sobre criatividade. Esses dados podem estar relacionados com a ampliação dos campos de atuação da psicologia enquanto profissão e com o reconhecimento de se trabalhar com essa temática em locais diversos e com públicos variados.

Em relação aos sujeitos das investigações, verificou-se que: 26,6 \% são alunos, sejam do ensino regular, médio, superior ou de contextos não formais, como aulas de dança; $11,8 \%$ são professores, sejam do ensino regular, médio, superior ou de outros contextos, como em um estudo que se refere a educadores afro-descendentes; 11,8\% são empregados em empresas/organizações; 11,8\% são artistas; $10,2 \%$ dos estudos investigaram ao mesmo tempo alunos e professores; 10,2 \%, usuários de instituições; e $8,5 \%$, grupos. Por fim, dos 59 estudos subcategorizados quanto aos sujeitos, $5(8,5 \%)$ foram classificados como outros, categoria que inclui sujeitos referidos como idosos, mulheres, casais, homens e mulheres.

Santos (1995), ao categorizar os trabalhos empíricos quanto aos sujeitos, não conseguiu subcategorizar 7 dos 48 trabalhos que analisou. Dos 41 categorizados, 83\% foram trabalhos com alunos; $14,6 \%$ com professores; e $2,4 \%$ com outros sujeitos. Neste aspecto também se constatam diferenças significativas nos dois períodos analisados, sendo a produção científica da última década caracterizada pela diversidade de sujeitos investigados, ainda que aproximadamente $50 \%$ deles tenham sido alunos e/ou professores.

Em relação ao tema principal em foco nos trabalhos analisados nesta investigação, destaca-se que: 39,7\% dos trabalhos trataram de alguma questão relacionada com $a$ prática pedagógica, incluindo aqueles com ênfase no aluno ou no professor; $22,1 \%$ enfatizaram questões relacionadas a vivências estéticas/criativas, principalmente com ênfase em artistas; $10,3 \%$ trataram de questões relacionadas com a prática do psicólogo nas empresas/organizações; $8,8 \%$ temas referentes à prática psicológica na Saúde; 8,8\% de avaliação/caracterização do sujeito criativo; $7,4 \%$ de concepções de criatividade/criação; e 2,9\% de outros temas.

Dos 68 trabalhos analisados nesta pesquisa, 22 foram caracterizados quanto ao uso de alguma linguagem artística. Destaca-se que 40,9\% desses 22 
trabalhos usaram artes plásticas/visuais; 13,6\%, literatura; 9\%, música; 4,6\% usaram dança/biodança; 4,6\% teatro; e 27,3\% usaram linguagens híbridas, ou seja, mais de uma linguagem artística.

Quanto ao referencial teórico utilizado nos trabalhos, obtiveram-se os seguintes resultados: abordagem psicométrica, 33,8\% dos trabalhos; abordagem psicanalítica, 19,1\%; abordagens híbridas, 7,4\%; abordagem fenomenológica, 5,9\%; abordagem históricocultural, 4,4\%; e outras abordagens, que utilizaram referenciais como os de Jung, Nietzsch, Deleuze e Guatarri, $8,8 \%$. Por fim, $20,6 \%$ dos trabalhos não puderam ser classificados quanto ao referencial teórico, por omitirem nos resumos informações que permitissem essa categorização. Destaca-se que nenhum dos resumos analisados apresenta os referenciais da teoria de investimento em criatividade de Sternberg, do modelo componencial de criatividade de Amabile ou da perspectiva de sistemas de Csikszentmihalyi, apontados por Alencar e Fleith (2003) como teorias que enfatizam os aspectos sociais, culturais e históricos envolvidos em uma perspectiva multidimensional para o estudo da criatividade.

Santos (1995) classificou os trabalhos em sua pesquisa nas seguintes abordagens: psicométrica, comportamental, psicogenética, psicosociológica, humanista e fenomenológica. Dos 59 trabalhos que analisou, 18 (30,5\%) não puderam ser classificados quanto à abordagem de estudo. Dentre as abordagens citadas, as que apresentaram maior incidência foram a comportamental e a psicométrica, com 43,9\% e 29,2\% respectivamente. Pode-se observar que a abordagem psicométrica se mantém nos dois períodos investigados com aproximadamente $30 \%$ dos estudos.

Santos (1995), ao investigar o "Diretório dos Grupos de Pesquisa no Brasil/CNPq" em 1993, identificou apenas um grupo que estudava o tema criatividade, situado em Brasília e com projeção internacional. Conforme pesquisa realizada nesse Diretório (CNPq, 2005), utilizando a palavra-chave criatividade para as áreas de Ciências Humanas/Psicologia, foram encontrados 11 grupos que investigam a temática criatividade (Ver Tabela 3). Diferenças são observadas quando da análise das linhas de pesquisa encontradas, na medida em que em algumas a criatividade é foco e em outras está relacionada a temáticas diversas. Além disso, constata-se que vários pesquisadores destes grupos também são orientadores de teses/dissertações analisadas nesta investigação.

\section{CONSIDERAÇÕES FINAIS}

A análise da produção científica sobre a temática criatividade nas teses e dissertações de programas de pós-graduação em Psicologia no Brasil na última década - 1994-2001 - sinaliza a ocorrência de mudanças significativas, se comparada com a produção de 1970 a 1993; por outro lado, continuidades também foram evidenciadas. Ressaltamos que a pesquisa de Santos (1995) abrangia os resumos de teses e dissertações do programas de pós-graduação em Psicologia e em Educação e a ora empreendida restringiu-se aos programas de pósgraduação em Psicologia.

Apesar de a pesquisa realizada referir-se a apenas uma área do saber, evidencia-se o aumento significativo de produções científicas sobre criatividade, considerandose que Santos (1995) encontrou 59 teses/dissertações no período de 1970 a 1993, enquanto de 1994 a 2001 foram encontrados 68 trabalhos apenas na área da Psicologia. Wechsler e Nakano (2003) também constataram o aumento do número de produções científicas sobre esta temática, incluindo-se teses/dissertações e artigos. Isso pode ser resultado da expansão dos programas de pósGraduação em Psicologia no Brasil e ao mesmo tempo indicador da importância atribuída a esta temática no contexto contemporâneo, podendo estar relacionado, entre outros fatores, à relevância da criatividade tanto para a reflexão sobre o psiquismo humano e sua constituição quanto para as intervenções psicológicas. Afirma Lev S. Vygotsky (1993) que o processo criador permite ao ser humano reelaborar e criar a partir de elementos de experiências passadas e presentes, projetando-se no futuro. A pesquisa sobre a temática é, portanto, fundamental se o compromisso assumido, enquanto ciência e profissão, volta-se para a emancipação humana e a potencialização da vida.

Se por um lado constata-se este aumento nas produções sobre criatividade nos últimos anos, por outro observa-se que metade das pesquisas continuam vinculadas a teorias tradicionais da Psicologia: aproximadamente $50 \%$ dos estudos aqui investigados são fundamentados nas abordagens psicométrica e psicanalítica.

A concentração de trabalhos na Região Sudeste e na Centro-Oeste, por sua vez, explicita uma realidade social marcada pela distribuição desigual da produção científica. Necessário, no entanto, esclarecer que a maioria dos programas de pós-graduação em Psicologia se encontram na Região Sudeste brasileira, porém recebem alunos de diversos estados brasileiros, os quais, por sua vez, deveriam se constituir como porta-vozes e divulgadores dessa produção.

Permanece também o predomínio da pesquisa experimental, porém em percentual significativamente menor que no período analisado por Santos (1995). O crescimento dos estudos de caso pode indicar mudanças 
no que se refere às indicações metodológicas dos programas de pós-graduação, que podem estar mais suscetíveis ao acolhimento de trabalhos que buscam aprofundar análises qualitativas a partir de situações específicas. Por sua vez, se até 1993 predominavam investigações realizadas em contextos escolares, na última década constata-se uma diversificação considerável quanto ao lócus da pesquisa, o que de certa forma expressa o interesse e inserção de psicólogos em contextos sociais variados. A diversidade de sujeitos também foi constatada, bem como alguns estudos que trabalham não somente com um segmento mas com foco em relações, caso das pesquisas que trabalharam com professores e alunos.

Também se pode observar, pela variedade dos grupos e dos temas encontrados, que a criatividade, além de aparecer como foco de algumas investigações, também é relacionada com uma diversidade de temáticas.

A Educação aparece como área privilegiada de estudos sobre esta temática, com foco na avaliação da criatividade de professores/alunos e treinamento, entre outros. Wechsler e Nakano (2003) também constataram que o enfoque predominante nas teses e dissertações tem sido o educacional, identificando problemas e propondo sugestões para a melhoria da educação brasileira por meio da criatividade. Interessa saber com que objetivo e a partir de que concepção de sujeito se deseja avaliar ou desenvolver sujeitos criativos - se voltados para a autonomia e emancipação dos sujeitos, mediados por atividades criativas que se produzem a partir de condições sociais e históricas, ou em concepções meramente reprodutivistas, posto que a criatividade é concebida como condição apriorística de sujeitos a-históricos. A resposta a essa questão, no entanto, só é possível com a investigação em profundidade desses trabalhos, o que foge ao escopo desta pesquisa.

Por fim, gostaríamos de destacar que a qualidade dos resumos analisados constitui uma limitação para as análises empreendidas. Diversos resumos não deixavam claros aspectos importantes como referencial teórico utilizado, método de pesquisa, entre outros. Esses problemas também foram relatados por Ferreira (2002) e por Santos (1995), apontando a necessidade de maior atenção por parte dos pesquisadores na elaboração dos resumos e na utilização das palavras-chave. A análise de resumos, no entanto, continua sendo relevante na medida em que possibilita certo rastreamento do já construído, orientando o leitor na pesquisa bibliográfica de um determinada área.

\section{REFERÊNCIAS}

Alencar, E. M. L. S. \& Fleith, D. S. (2003). Contribuições teóricas recentes ao estudo da criatividade. Psicologia: Teoria e Pesquisa, 19(1), 1-8

Coordenação de Aperfeiçoamento de Pessoal de Nível Superior/CAPES. (2004). Banco de Teses. Disponível em $<\mathrm{http}: / /$ www.capes.gov.br/capes/portal/conteudo/10/Teses_Disserta coes.htm>. (Acessado em 01/10/2004).

Conselho Nacional de Desenvolvimento Científico e Tecnológico/CNPq (2005). Diretório dos Grupos de Pesquisa no Brasil. Disponível em: <http://lattes.cnpq.br/buscaoperacional>. (Acessado em 14/03/2005).

Ferreira, N. S. A. (2002). As pesquisas denominadas "estado da arte". Educação e Sociedade: Revista quadrimestral de Ciência da Educação, 9(1), 257-272.

Francisco, P. R. (2002). Tendências nas dissertações e teses em Psicologia sobre as dificuldade de aprendizagem escolar na segunda metade da década de 90. Dissertação de Mestrado, NãoPublicada. Programa de Pós-Graduação em Psicologia, Universidade Federal de Santa Catarina, Florianópolis, SC.

Minayo, M. C. S. (1999, $6^{\text {a }}$ ed.). $O$ desafio do conhecimento: pesquisa qualitativa em saúde. São Paulo/Rio de Janeiro: Hucitec/Abrasco.

Santeiro, T.V., Santeiro, F. R. M. \& Andrade, I. R. (2004). Professor facilitador e inibidor da criatividade segundo universitários. Psicologia em Estudo, 9(1), 95-102.

Santos, A.T. (1995). Estudo da criatividade no Brasil: análise das teses/dissertações em Psicologia e Educação (1970/1993). Dissertação de Mestrado, Faculdade de Educação, Universidade Estadual de Campinas.

Vasconcelos, M. S. (Org.) (2001). Criatividade, psicologia, educação e conhecimento do novo. São Paulo: Moderna.

Vygotski, L.S. (1993). La imaginación y el arte en la infancia. Madrid: Akal.

Wechsler, S. M. \& Nakano T. C. (2003). Produção científica brasileira em criatividade: o estado da arte. Escritos Educacionais, 2(2), 43-50.

Recebido em 25/10/2005 Aceito em 30/04/2005

Endereço para correspondência: Andréa Vieira Zanella, Universidade Federal de Santa Catarina/ Pós-Graduação em Psicologia, Campus Trindade, CEP 88010-970, Florianópolis-SC. E-mail: azanella@cfh.ufsc.br 


\section{ANEXOS}

Tabela 1. Estudos em que consta a palavra criatividade nas palavras-chave do resumo

\begin{tabular}{|c|c|c|c|c|c|}
\hline Autor (a) & Instituição & Título & Nível & Ano & Orientador(a) \\
\hline $\begin{array}{l}\text { Adriana Mabel } \\
\text { Fresquet }\end{array}$ & UNB & $\begin{array}{l}\text { O processo de co-construção do conceito de criatividade } \\
\text { por professores de educação infantil: uma análise } \\
\text { microgenética }\end{array}$ & M & 2000 & $\begin{array}{l}\text { Albertina M.Martinez; Diva } \\
\text { M }^{\text {a }} \text { M. de Albuquerque Maciel }\end{array}$ \\
\hline $\begin{array}{l}\text { Alessandra Mara dos } \\
\text { Santos Dutra }\end{array}$ & PUC-SP & A criatividade na saúde & M & 2001 & $\begin{array}{l}\text { Silvia Regina Eulalio de } \\
\text { Souza }\end{array}$ \\
\hline $\begin{array}{l}\text { Alida Ionescu } \\
\text { Brunow de Carvalho }\end{array}$ & PUC-SP & $\begin{array}{l}\text { A busca de um modelo de transformação do self na vida } \\
\text { adulta: um relato autobiográfico de Marion Milner. }\end{array}$ & M & 1994 & Gilberto Safra \\
\hline $\begin{array}{l}\text { Amélia Maria Leal } \\
\text { Righetti }\end{array}$ & UFRJ & $\begin{array}{l}\text { A atividade criativa como introdutora da criança na } \\
\text { experiência cultural }\end{array}$ & M & 1996 & $\begin{array}{l}\text { Jacyara Carrijo Rochael } \\
\text { Nasciutti }\end{array}$ \\
\hline $\begin{array}{l}\text { Ana Cristina Ristow } \\
\text { Wolff }\end{array}$ & PUCCAMP & $\begin{array}{l}\text { O corpo dança expressa e cria: formação de professores de } \\
\text { Educação Física }\end{array}$ & M & 1997 & Solange Muglia Wechsler \\
\hline $\begin{array}{l}\text { Andréa Ricardo de } \\
\text { Mazzieri Rathasam }\end{array}$ & PUC-SP & $\begin{array}{l}\text { Nem tudo é exílio - reflexões sobre a criatividade no } \\
\text { processo psicoterápico de pacientes psicóticos }\end{array}$ & M & 1999 & Gilberto Safra \\
\hline Carmem Lúcia Reis & PUCCAMP & $\begin{array}{l}\text { Escala de adjetivos contextualizados para avaliação da } \\
\text { pessoa criativa }\end{array}$ & M & 2001 & Solange Wechsler \\
\hline $\begin{array}{l}\text { Cassia Aparecida } \\
\text { Bignetti }\end{array}$ & PUCCAMP & $\begin{array}{l}\text { Efeitos de um programa para o desenvolvimento da } \\
\text { criatividade verbal através do contar histórias. }\end{array}$ & M & 1995 & Solange Muglia Wechsler \\
\hline $\begin{array}{l}\text { Christina M. B. } \\
\text { Cupertino }\end{array}$ & PUC-SP & $\begin{array}{l}\text { O resgate do marginal: atividades impertinentes para } \\
\text { psicólogos em formação. }\end{array}$ & $\mathrm{D}$ & 1995 & $\begin{array}{l}\text { Luis Cláudio Mendonça } \\
\text { Figueiredo }\end{array}$ \\
\hline Claudia J. Silva & UFRJ & Criação e Sociedade & $\mathrm{D}$ & 2001 & Lucia R. de Castro \\
\hline $\begin{array}{l}\text { Cleusa Kazue } \\
\text { Sakamoto }\end{array}$ & USP & $\begin{array}{l}\text { A criatividade sob a luz da experiência: a busca de uma } \\
\text { visão integradora do fenômeno criativo }\end{array}$ & $\mathrm{D}$ & 1999 & Edda Bomtempo \\
\hline $\begin{array}{l}\text { Cristina Vilela de } \\
\text { Carvalho }\end{array}$ & USP & $\begin{array}{l}\text { Em Busca de uma obra: considerações psicanalíticas sobre } \\
\text { o processo de elaboração de uma dissertação de mestrado. }\end{array}$ & M & 1994 & Adail Victorino Castilho \\
\hline $\begin{array}{l}\text { Cyntia Cleusa } \\
\text { Pasquia Mayer } \\
\text { Tibeau }\end{array}$ & PUC-SP & $\begin{array}{l}\text { Criatividade e criatividade motora: características, } \\
\text { indicadores e sua importância na formação do profissional } \\
\text { de educação física }\end{array}$ & $\mathrm{D}$ & 2001 & $\begin{array}{l}\text { Maria Laura Puglisi Barbosa } \\
\text { Franco }\end{array}$ \\
\hline Denise Bragotto & PUCCAMP & $\begin{array}{l}\text { Programa Experimental para o desenvolvimento da } \\
\text { expressão poética em adolescentes. }\end{array}$ & M & 1994 & Solange Muglia Wechsler \\
\hline $\begin{array}{l}\text { Denise Ramalho } \\
\text { Dantas }\end{array}$ & USP & O amor no feminino: ocultamento e/ou revelação? & $\mathrm{D}$ & 2001 & Gilberto Safra \\
\hline $\begin{array}{l}\text { Fabrícia Teixeira } \\
\text { Borges }\end{array}$ & $\mathrm{UNB}$ & $\begin{array}{l}\text { Habilidades de pensamento criativo em professores de } \\
\text { escolas tradicionais e escolas inovadoras }\end{array}$ & M & 1997 & $\begin{array}{l}\text { Eunice Maria Lima Soriano de } \\
\text { Alencar }\end{array}$ \\
\hline $\begin{array}{l}\text { Iara Guadalupe } \\
\text { Garcia }\end{array}$ & PUCCAMP & $\begin{array}{l}\text { Consultoria escolar: percepção de diretores de escola } \\
\text { pública estadual. }\end{array}$ & M & 1999 & Solange Muglia Wechsler \\
\hline $\begin{array}{l}\text { Jamili Rasoul Salem } \\
\text { de Souza }\end{array}$ & UMESP & O trabalho junto ao superdotado em nossa realidade & M & 2001 & Vera Maria Barros de Oliveira \\
\hline Jóia Eliezer & USP & $\begin{array}{l}\text { A criatividade e elaboração artística em estudantes de } \\
\text { artes plásticas. }\end{array}$ & M & 2000 & Jussara Falek Brauer \\
\hline $\begin{array}{l}\text { Luciana Gurgel } \\
\text { Guida Siqueira }\end{array}$ & PUCCAMP & $\begin{array}{l}\text { Estilos de criar e rendimento escolar: análise da influência } \\
\text { do sexo e da escolaridade }\end{array}$ & M & 2001 & Solange Wechsler \\
\hline $\begin{array}{l}\text { Marcos Antonio da } \\
\text { Cunha }\end{array}$ & PUCCAMP & $\begin{array}{l}\text { Expressões criativas na cultura afro-brasileira: percepção } \\
\text { de educadores }\end{array}$ & M & 1999 & Solange Muglia Wechsler \\
\hline $\begin{array}{l}\text { Maria Alice D'Avila } \\
\text { Becker }\end{array}$ & PUC-RS & $\begin{array}{l}\text { Criatividade, abstração, raciocínio lógico, ansiedade e sua } \\
\text { interação na personalidade de estudantes de arquitetura, } \\
\text { computação e psicologia }\end{array}$ & $\mathrm{D}$ & 2001 & Cicero Emidio Vaz \\
\hline $\begin{array}{l}\text { Maria Cristina } \\
\text { Rodrigues Azevedo } \\
\text { Jolly }\end{array}$ & USP & $\begin{array}{l}\text { Microcomputador e criatividade em leitura e escrita no } \\
\text { ensino fundamental }\end{array}$ & D & 1999 & $\begin{array}{l}\text { José Fernando Bitencourt } \\
\text { Lomônaco }\end{array}$ \\
\hline $\begin{array}{l}\text { Maria de Fátima } \\
\text { Bruno de Faria }\end{array}$ & UNB & $\begin{array}{l}\text { Estímulos e barreiras à criatividade no ambiente de } \\
\text { trabalho de uma instituição bancário }\end{array}$ & M & 1996 & $\begin{array}{l}\text { Eunice Maria Lima Soriano de } \\
\text { Alencar }\end{array}$ \\
\hline
\end{tabular}


Tabela 1. Estudos em que consta a palavra criatividade nas palavras-chave do resumo (Continuação)

\begin{tabular}{|c|c|c|c|c|c|}
\hline Autor (a) & Instituição & Título & Nível & Ano & Orientador(a) \\
\hline $\begin{array}{l}\text { Maria de Fátima } \\
\text { Guerreiro Godoy }\end{array}$ & PUCCAMP & Criatividade e integração vital com idosos & M & 1996 & Solange Muglia Wechsler \\
\hline $\begin{array}{l}\text { Maria de Fátima M. } \\
\text { Mariani }\end{array}$ & UCB & $\begin{array}{l}\text { Criatividade e trabalho pedagógico: limites e } \\
\text { possibilidades na expressão da criatividade do professor } \\
\text { de história }\end{array}$ & M & 2001 & $\begin{array}{l}\text { Eunice Maria Lima Soriano de } \\
\text { Alencar }\end{array}$ \\
\hline $\begin{array}{l}\text { Maria Luisa Furlin } \\
\text { Bampi }\end{array}$ & PUCCAMP & $\begin{array}{l}\text { Efeitos de um programa para o desenvolvimento da } \\
\text { criatividade na escrita }\end{array}$ & M & 1995 & Solange Muglia Wechsler \\
\hline $\begin{array}{l}\text { Maria Luisa Furlin } \\
\text { Bampi }\end{array}$ & USP & $\begin{array}{l}\text { Programa para o desenvolvimento da leitura e escrita: faz- } \\
\text { de-conta }\end{array}$ & $\mathrm{D}$ & 2000 & Edda Bomtempo \\
\hline Marilúcia F. Crespo & PUCCAMP & $\begin{array}{l}\text { Clima criativo: um diagnóstico para inovação nas } \\
\text { organizações educacionais e empresariais }\end{array}$ & M & 1997 & Solange Muglia Wechsler \\
\hline $\begin{array}{l}\text { Marisa Cintrão } \\
\text { Forghieri }\end{array}$ & USP & Criatividade e Psicologia em oficina. & M & 1995 & João Augusto Frayze-Pereira \\
\hline $\begin{array}{l}\text { Mônica Souza Neves } \\
\text { Pereira }\end{array}$ & UNB & $\begin{array}{l}\text { Efeitos de um treinamento de criatividade no desempenho } \\
\text { escolar e nas habilidades criativas de crianças com } \\
\text { dificuldades de aprendizagem }\end{array}$ & M & 1996 & $\begin{array}{l}\text { Eunice Maria Lima Soriano de } \\
\text { Alencar }\end{array}$ \\
\hline $\begin{array}{l}\text { Montserrat } \\
\text { Mantovani Vinas }\end{array}$ & PUC-SP & Religião: criatividade ou defesa da psique? & M & 1994 & $\begin{array}{l}\text { Luis Cláudio Mendonça } \\
\text { Figueiredo }\end{array}$ \\
\hline $\begin{array}{l}\text { Patrícia Pinna } \\
\text { Bernardo }\end{array}$ & USP & $\begin{array}{l}\text { A "doce medicina": trabalhando com a sabedoria da } \\
\text { psique na criação de um conhecimento integrado ao auto- } \\
\text { conhecimento. }\end{array}$ & $\mathrm{D}$ & 2001 & $\begin{array}{l}\text { Maria Luisa Sandoval } \\
\text { Schmidt }\end{array}$ \\
\hline $\begin{array}{l}\text { Rosana Maria } \\
\text { Bertonha }\end{array}$ & PUCCAMP & $\begin{array}{l}\text { Programa de desenvolvimento da criatividade em crianças } \\
\text { pré-escolares. }\end{array}$ & M & 1995 & Solange Muglia Wechsler \\
\hline Rute P. F.Pereira & PUCCAMP & $\begin{array}{l}\text { Pesquisador, questionar e criar: percepção de alunos do } \\
\text { curso de Pedagogia }\end{array}$ & M & 1998 & Solange Muglia Wechsler \\
\hline $\begin{array}{l}\text { Sandra Augusta de } \\
\text { Melo }\end{array}$ & PUCCAMP & A transfiguração criativa da realidade & $\mathrm{D}$ & 1999 & Maria Emília Lino da Silva \\
\hline $\begin{array}{l}\text { Sebastião R. Gois } \\
\text { Moreira }\end{array}$ & PUCCAMP & $\begin{array}{l}\text { Epilepsia e criatividade: um estudo com crianças de } \\
\text { escolas públicas }\end{array}$ & M & 1995 & Solange Muglia Wechsler \\
\hline $\begin{array}{l}\text { Suselaine Serejo } \\
\text { Martinelli }\end{array}$ & UNB & $\begin{array}{l}\text { No ensino, quem dança? Uma análise crítica sobre a } \\
\text { criatividade no ensino da dança no DF. Brasília }\end{array}$ & M & 2000 & $\begin{array}{l}\text { Albertina Mitjáns Martinez; } \\
\text { Silviane Bonaccorsi Barbato }\end{array}$ \\
\hline Tales Vilela Santeiro & PUCCAMP & $\begin{array}{l}\text { Criatividade em psicanálise: produção científica (1990- } \\
\text { 1999) }\end{array}$ & M & 2000 & Elisa Medici Pizão Yoshida \\
\hline $\begin{array}{l}\text { Tania } M^{\mathrm{a}} \text { Guedes } \\
\text { Henriques }\end{array}$ & PUCCAMP & $\begin{array}{l}\text { Características da liderança criativa em organizações } \\
\text { públicas e privadas }\end{array}$ & M & 1999 & Solange Muglia Wechsler \\
\hline $\begin{array}{l}\text { Vieira Fernanda } \\
\text { Alice Gomes }\end{array}$ & UFRJ & Alienação versus criatividade na sociedade tanática & M & 1994 & Antonio Gomes Penna \\
\hline
\end{tabular}

Tabela 2. Estudos que apresentaram como tema, nos resumos, a questão da criatividade

\begin{tabular}{|c|c|c|c|c|c|}
\hline $\operatorname{Autor}(\mathbf{a})$ & Instituição & Título & Nível & Ano & Orientador(a) \\
\hline $\begin{array}{l}\text { Ana Paula Melchiors } \\
\text { Stahlschmidt }\end{array}$ & PUC-RS & $\begin{array}{l}\text { Brincando de fazer arte - a música e outras } \\
\text { manifestações artísticas: a inserção social da criança } \\
\text { com dificuldades de aprendizagem }\end{array}$ & M & 1998 & Juracy C. Marques \\
\hline $\begin{array}{l}\text { Andrea Pacetta de Arruda } \\
\text { Botelho }\end{array}$ & USP & $\begin{array}{l}\text { No universo das histórias: oficinas de redação e } \\
\text { criatividade }\end{array}$ & M & 1998 & Lino de Macedo \\
\hline $\begin{array}{l}\text { Cristiane Brandão Ribeiro } \\
\text { Mendes }\end{array}$ & UNB & $\begin{array}{l}\text { Nos espelhos da arte - reflexões psicanalíticas sobre a } \\
\text { apreciação estética. }\end{array}$ & M & 2000 & Tania Cristina Rivera \\
\hline $\begin{array}{l}\text { Giuliana Gnatos João Lima } \\
\text { Bilbao }\end{array}$ & PUCCAMP & $\mathrm{O}$ artista e sua arte: um estudo fenomenológico & M & 2001 & Vera Engler Cury \\
\hline Jacila Maria da Silva & UFRJ & $\begin{array}{l}\text { A música da psicanálise - um estudo da singularidade a } \\
\text { partir da criação artística }\end{array}$ & M & 2000 & Joel Birman \\
\hline Janice Inchauspe Pereira & PUC-RS & $\begin{array}{l}\text { Momentos críticos na vida adulta e suas possibilidades } \\
\text { criativas }\end{array}$ & $\mathrm{D}$ & 2001 & Juracy Cunegatto Marques \\
\hline $\begin{array}{l}\text { José Maurício Mangueira } \\
\text { Viana }\end{array}$ & PUC-SP & $\begin{array}{l}\text { Microfísica das criações parciais - a partir de Nietzasche } \\
\text { e Deleuza }\end{array}$ & $\mathrm{D}$ & 1997 & Suely Belinha Rolnik \\
\hline Lígia Hecker Ferreira & PUC-SP & O mal estar na escola: uma pragmática ético-estética & M & 1998 & Suely Belinha Rolnik \\
\hline
\end{tabular}


Tabela 2. Estudos que apresentaram como tema, nos resumos, a questão da criatividade (Continuação)

\begin{tabular}{|c|c|c|c|c|c|}
\hline Autor(a) & Instituição & Título & Nível & Ano & Orientador(a) \\
\hline Luciana Lobo Miranda & PUC-RIO & $\begin{array}{l}\text { Produção de subjetividade: por uma estética da } \\
\text { existência }\end{array}$ & M & 1996 & Maria Helena Novaes Mira \\
\hline Marcia Murinelly Gomes & USP & $\begin{array}{l}\text { Oficinas com recursos expressivos: espaços de interação } \\
\text { para a expressão e a reflexão na formação de educadores }\end{array}$ & M & 2000 & Edda Bomtempo \\
\hline Maria G.C. Ferraz & PUC-SP & Religare, uma cartografia da fé. & $\mathrm{D}$ & 1994 & Suely B. Rolnik \\
\hline $\begin{array}{l}\text { Maria de Lourdes Motta } \\
\text { Machado }\end{array}$ & UFMG & $\begin{array}{l}\text { Sujeito e trabalho: impasses e possibilidades frente às } \\
\text { novas tecnologias de gestão no trabalho: o caso Gessy } \\
\text { Lever }\end{array}$ & M & 1999 & $\begin{array}{l}\text { Ricardo Augusto Alves de } \\
\text { Carvalho }\end{array}$ \\
\hline Marise Aparecida de Lima & PUC-SP & $\begin{array}{l}\text { Círculos de controle de qualidade-CCQ: apontamentos } \\
\text { para a compreensão dos aspectos subjetivos envolvidos } \\
\text { nesse processo }\end{array}$ & M & 1997 & Odair Sass \\
\hline $\begin{array}{l}\text { Patrícia Aparecida Nunes e } \\
\text { Silva }\end{array}$ & PUCCAMP & $\begin{array}{l}\text { Avaliação do perfil da criatividade do professor no } \\
\text { Ensino Médio }\end{array}$ & $\mathrm{M}$ & 2000 & Solange Muglia Wechsler \\
\hline Robson Jesus Rusche & USP & $\begin{array}{l}\text { Teatro: Gesto e Atividade. Investigando processos } \\
\text { educativos através de técnicas dramáticas, com um } \\
\text { grupo de presidiários. }\end{array}$ & $\mathrm{M}$ & 1997 & Lígia Assumpção Amaral \\
\hline Rosana de Almeida & UMESP & $\begin{array}{l}\text { Criatividade e relações objetais pelo Rorschach e } \\
\text { Phillipson em dois pintores }\end{array}$ & M & 1994 & José Tolentino Rosa \\
\hline Rosângela da Luz Mattos & UFRGS & $\begin{array}{l}\text { Capital, trabalho e subjetivação: a juventude nas malhas } \\
\text { do setor de serviços }\end{array}$ & M & 2001 & Tania Mara Galli Fonseca \\
\hline Selma S.Leite Flores & PUC-SP & Estética de uma existência & M & 2000 & Luiz B.L.Orlandi \\
\hline Silvana Maria Rea & USP & $\begin{array}{l}\text { Transformatividade - Renina Katz, Carlos Fajardo, } \\
\text { Flávia Ribeiro... Aproximações entre artes plásticas e } \\
\text { psicanálise }\end{array}$ & M & 1998 & $\begin{array}{l}\text { João Augusto Frayze- } \\
\text { Pereira }\end{array}$ \\
\hline Silvana Mendes Lima & PUC-RIO & Subjetividade infantil e seus movimentos de autonomia & M & 1996 & Lucia Rabello de Castro \\
\hline Simonetta Persichetti & PUC-SP & $\begin{array}{l}\text { A poética no olho crítico - a estética como formadora de } \\
\text { discurso na fotografia documental latino-americana. }\end{array}$ & $\mathrm{D}$ & 2001 & Silvia Tatiana Maurer Lane \\
\hline $\begin{array}{l}\text { Sonia Maria B. } \\
\text { Albuquerque Parente }\end{array}$ & PUC-SP & $\begin{array}{l}\text { Inibição intelectual: o paradoxo no sintoma expressando } \\
\text { paralisia e busca da criatividade: uma visão } \\
\text { winnicottiana }\end{array}$ & M & 1996 & Gilberto Safra \\
\hline $\begin{array}{l}\text { Tereza Maria Salles da } \\
\text { Costa Lima }\end{array}$ & PUC-SP & $\begin{array}{l}\text { Desenhando o Viver. Uma investigação sobre o viver } \\
\text { criativo a partir do pensamento de Marion Milner. }\end{array}$ & M & 2000 & Gilberto Safra \\
\hline Terezinha Mello da Silveira & PUC-RIO & $\begin{array}{l}\text { A construção criativa na vida do casal: limites e } \\
\text { possibilidades do casamento contemporâneo }\end{array}$ & M & 1998 & Terezinha Féres Carneiro \\
\hline Vera Lucia Pasini & PUC-RS & $\begin{array}{l}\text { Encontros e desencontros: uma cartografia das máscaras } \\
\text { do amor na contemporaneidade }\end{array}$ & M & 1997 & $\begin{array}{l}\text { Nara Maria Guazzelli } \\
\text { Bernardes }\end{array}$ \\
\hline Yara B. Caznok & USP & Música: entre o audível e o visível & $\mathrm{D}$ & 2001 & João A.Frayze-Pereira \\
\hline Yara M.C. Pinto & PUC-RIO & A relação entre narcisismo e genialidade & M & 1995 & Maria Helena Mira Novaes \\
\hline
\end{tabular}

Tabela 3. Grupos de Pesquisa que investigam a temática criatividade, com seus respectivos pesquisadores e linhas de pesquisa $(\mathrm{CNPq}, 2005)$

\begin{tabular}{|c|c|c|}
\hline Grupo de Pesquisa/ Instituição & Linhas de Pesquisa $^{2}$ & Pesquisadores \\
\hline $\begin{array}{l}\text { 1. Aprendizagem Significativa na } \\
\text { Formação de Profissionais de Saúde e } \\
\text { Educação - USP }\end{array}$ & 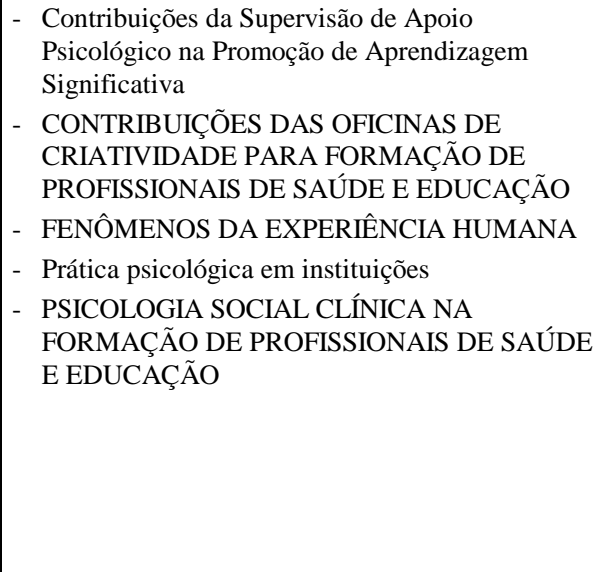 & $\begin{array}{l}\text { Ana Lúcia Francisco } \\
\text { Angela Nobre de Andrade } \\
\text { Christina Menna Barreto Cupertino } \\
\text { Dulce Mara Critelli } \\
\text { Elza Maria do Socorro Dutra } \\
\text { Gohara Yvette Yehia } \\
\text { Heloisa Szymanski } \\
\text { Henriette T. Penha Morato (Líder) } \\
\text { Jesus Vazquez Torres } \\
\text { Marcia Alves Tassinari } \\
\text { Marcus Túlio Caldas } \\
\text { Maria L. Sandoval Schmidt (Líder) } \\
\text { Nilson Gomes Vieira Filho } \\
\text { Sheva Maia da Nóbrega } \\
\text { Silvia Ancona-Lopez } \\
\text { Vera Engler Cury }\end{array}$ \\
\hline
\end{tabular}

2 Linhas de pesquisa que explicitaram a temática criatividade estão em caixa alta. 
Tabela 3. Grupos de Pesquisa que investigam a temática criatividade, com seus respectivos pesquisadores e linhas de pesquisa $(\mathrm{CNPq}, 2005)$

\begin{tabular}{|c|c|c|}
\hline Grupo de Pesquisa/ Instituição & Linhas de Pesquisa & Pesquisadores \\
\hline $\begin{array}{l}\text { As mediações: as emoções, a } \\
\text { linguagem e os grupos sociais - } \\
\text { PUC/SP }\end{array}$ & $\begin{array}{l}\text { - } \text { ANÁLISE CRÍTICA DAS CATEGORIAS } \\
\text { PRESENTES NA PSICOLOGIA SOCIAL } \\
\text { - Emoções em Culturas Indígenas }\end{array}$ & $\begin{array}{l}\text { Maria da G. Marchina Gonçalves } \\
\text { Maria H. de Mendonça Coelho } \\
\text { Silvia Tatiana Maurer Lane (Líder) }\end{array}$ \\
\hline $\begin{array}{l}\text { 3. Constituição do Sujeito e Atividade } \\
\text { Criadora em Contextos de Ensinar e } \\
\text { Aprender - UFSC }\end{array}$ & $\begin{array}{ll}\text { - } & \text { CONSTITUIÇÃO DO SUJEITO E ATIVIDADE } \\
& \text { CRIADORA } \\
\text { - } & \text { CONSTITUIÇÃO DO SUJEITO E } \\
& \text { FORMAÇÃO DE PROFESSORES } \\
\text { - } & \text { PRODUÇÃO IMAGINÁRIA NA ESCOLA }\end{array}$ & $\begin{array}{l}\text { Andrea Vieira Zanella (Líder) } \\
\text { Angel Pino (Líder) } \\
\text { Cassia Ferri } \\
\text { Kátia Maheirie } \\
\text { Luciane Maria Schlindwein } \\
\text { Silvia Zanatta Da Ros } \\
\text { Susana Inês Molon }\end{array}$ \\
\hline 4. $\quad$ Criatividade - UFAM & - CRIATIVIDADE & Maria Alice d'Avila Becker (Líder) \\
\hline $\begin{array}{l}\text { 5. Desenvolvimento Humano e Educação } \\
\text { Especial - UFMS }\end{array}$ & $\begin{array}{l}\text { - } \text { CRIATIVIDADE E EDUCAÇÃO } \\
\text { - Educação, Indivíduo e Sociedade } \\
\text { - Educação, Saúde e Deficiência } \\
\text { - } \text { Indivíduo, Cultura e Ideologia da Racionalidade } \\
\text { Tecnológica } \\
\text { - Psicologia, Educação e Saúde }\end{array}$ & $\begin{array}{l}\text { Alexandra Ayach Anache (Líder) } \\
\text { Aracy Mendes de Souza } \\
\text { Dulce R. dos Santos Pedrossian } \\
\text { Maria de L. Jeffery Contini (Líder) }\end{array}$ \\
\hline $\begin{array}{ll}6 . & \text { LAPES - LABORATÓRIO DE } \\
& \text { PSICOLOGIA ESCOLAR - UNB }\end{array}$ & 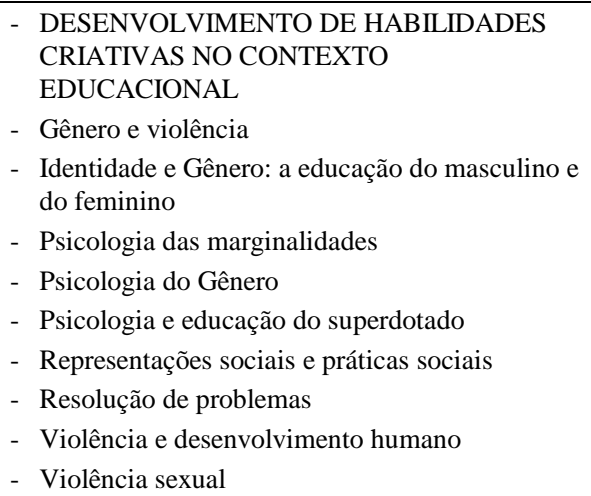 & $\begin{array}{l}\text { Ana Cristina Brito Arcoverde } \\
\text { Ana Lúcia Galinkin } \\
\text { Angela M. O. Almeida (Líder) } \\
\text { Denise de Souza Fleith (Líder) } \\
\text { Glaucia Ribeiro Starling Diniz } \\
\text { Helerina Aparecida Novo } \\
\text { Maria de Fatima de Souza Santos } \\
\text { Pedro Humberto Faria Campos } \\
\text { Zeidi Araujo Trindade }\end{array}$ \\
\hline $\begin{array}{l}\text { Laboratório de Avaliação e Medidas } \\
\text { em Psicologia - LAMP - PUC- } \\
\text { CAMPINAS }\end{array}$ & $\begin{array}{l}\text { - } \text { AVALIAÇÃO PSICOLÓGICA: DIMENSÃO } \\
\text { COGNITIVA E CRIATIVA } \\
\text { - } \text { Prevenção, comunidade e libertação }\end{array}$ & $\begin{array}{l}\text { Patrícia Waltz Schelini } \\
\text { Solange Wechsler (Líder) } \\
\text { Raquel Souza Lobo Guzzo (Líder) }\end{array}$ \\
\hline $\begin{array}{l}\text { 8. Processos Criativos e Superdotação - } \\
\text { UCB-DF }\end{array}$ & 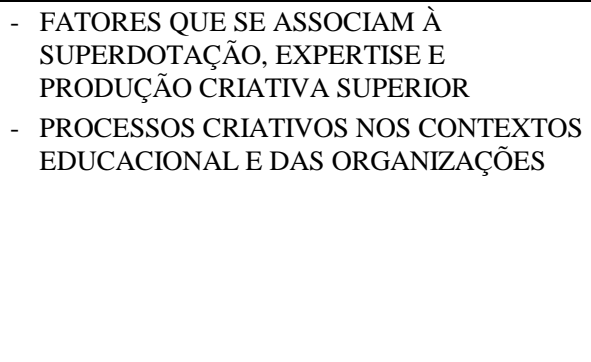 & $\begin{array}{l}\text { Afonso Celso Tanus Galvao } \\
\text { Albertina Mitjáns Martínez } \\
\text { Angela Mágda Rodrigues Virgolim } \\
\text { Denise de Souza Fleith } \\
\text { Eunice M. L. S. de Alencar (Líder) } \\
\text { Maria de Fátima Bruno de Faria } \\
\text { Maria Helena Novaes Mira } \\
\text { Mônica Souza Neves Pereira } \\
\text { Solange Wechsler }\end{array}$ \\
\hline $\begin{array}{l}\text { 9. Psicologia Construtivista e Educação - } \\
\text { CONE - UNESP }\end{array}$ & $\begin{array}{l}\text { - } \text { BRINCAR E CRIATIVIDADE } \\
\text { - } \text { Cognição, Afeto e Moralidade } \\
\text { - } \text { Moralidade e Espaços Educativos } \\
\text { - Processos Psicológicos, Disciplina e Indisciplina } \\
\text { Escolar } \\
\text { - Psicogênese da Segunda Língua }\end{array}$ & $\begin{array}{l}\text { Clary Milnitsky-Sapiro } \\
\text { Leonardo Lemos de Souza } \\
\text { Maria Elvira B. Martins dos Santos } \\
\text { Mário Sérgio Vasconcelos (Líder) } \\
\text { Nelson Pedro da Silva (Líder) } \\
\text { Rita Melissa Lepre }\end{array}$ \\
\hline
\end{tabular}


Tabela 3. Grupos de Pesquisa que investigam a temática criatividade, com seus respectivos pesquisadores e linhas de pesquisa (CNPq, 2005) (Continuação)

\begin{tabular}{|c|c|c|}
\hline Grupo de Pesquisa/ Instituição & Linhas de Pesquisa & Pesquisadores \\
\hline $\begin{array}{l}\text { 10. Psicologia: Educação e Saúde - } \\
\text { UNIVALI }\end{array}$ & $\begin{array}{l}\text { - Aspectos biopsicossociais da aprendizagem e do } \\
\text { desenvolvimento humano } \\
\text { - Avaliação Psicológica } \\
\text { - ESPIRITUALIDADE E QUALIDADE DE } \\
\text { VIDA } \\
\text { - Organização e gestão do trabalho } \\
\text { - Promoção em Educação e Saúde }\end{array}$ & $\begin{array}{l}\text { Aurino Ramos Filho } \\
\text { Carlos Eduardo Maximo } \\
\text { Eduardo Jose Legal } \\
\text { Elizabeth Navas Sanches } \\
\text { Jamir João Sardá Júnior } \\
\text { Josiane da Silva Delvan (Líder) } \\
\text { Katia Simone Ploner } \\
\text { Léia Viviane Fontoura } \\
\text { Lísia Regina Ferreira Michels } \\
\text { Maria Isabel do Nascimento André } \\
\text { Marina Menezes Giovana Delvan Stuhler Avi } \\
\text { Pedro Antônio Geraldi } \\
\text { Rosana Marques da Silva } \\
\text { Sergio Jacques Jablonski Junior }\end{array}$ \\
\hline $\begin{array}{l}\text { 11. Saúde Integral de Grupos em Situação } \\
\text { de Risco - ULBRA }\end{array}$ & $\begin{array}{l}\text { - } \text { Clínica, saúde e comunidade } \\
\text { - PROCESSOS DO DESENVOLVIMENTO E } \\
\text { DA APRENDIZAGEM }\end{array}$ & $\begin{array}{l}\text { Claudéte Inês Kronbauer Pohlit } \\
\text { Denise Machado Duran Gutierrez } \\
\text { Júlio Cesar Schweickardt (Líder) } \\
\text { Jussara Goncalves Lummertz } \\
\text { Maria Inês Gasparetto Higuchi } \\
\text { Sônia Maria Lemos (Líder) }\end{array}$ \\
\hline
\end{tabular}

